\title{
A new reinforced concrete beam
}

\author{
N. M. Elbasha \\ Department of Civil Engineering, Zawia University, Regdalin, Libya
}

\begin{abstract}
The introduction of high strength concrete and steel reduces the size of structural members whilst having the same load carrying capacity and a resultant saving on construction time, material, labour and space. Therefore, using both high strength steel and high strength concrete in construction is very important for producing a lightweight structure.

High strength concrete (HSC) and high strength steel are used together to increase a beam's load capacity and reduce its cross section. Using these two materials to design over-reinforced beams will reduce the size, weight and costs, which is a desirable result, but because they lack ductility, the current codes of practice disallow their use. This study shows that ductility can be significantly improved by installing helical confinement in the compression zone.

In the last 20 years there has been extensive research to economically utilize new components to improve the quality of HSC. HSC produces smaller but stronger structural elements with large spaces available. This proved that structures constructed with HSC are lighter and economical compared with those constructed with normal strength concrete (NSC).

This study presents recent information on the benefits of HSC and also provides, in brief, experimental proof that installing a helix with a suitable pitch and diameter in the compression zone of beams significantly enhances their strength and ductility. Therefore designers could confidently use HSC and helical confinement to design long and lightweight (by reducing the beam size) reinforced concrete beams.

Keywords: lightweight structures, reinforced concrete beams, high strength concrete, helical confinement.
\end{abstract}




\section{Introduction}

High strength concrete (HSC) has been used extensively in civil construction projects worldwide because it reduces the cross section and the weight of long construction members. In recent years a marked increase in the use of high strength concrete (HSC) has been evident in Australian building construction despite the fact that the current Australian design standard AS 3600 [1], provides no design rules for such a material. Very limited information on the properties of HSC and its design and construction processes are available in Australia, although in recent times many studies have been undertaken to produce material and, more importantly, to determine its characteristic.

In recent years, there have been significant improvements in the properties of concrete and steel reinforcing bars. Although high strength concrete and high strength steel have only recently begun to be used in Australia, researchers and construction companies have been encouraged to utilise them, because they are cost effective and have other advantages.

Primarily, high strength steel is extremely reliable, and grade 500 reinforcing bars provide high design strength. Being stronger, high strength steel is economical because it reduces the size and weight of the concrete member. Moreover, high strength steel can be welded by conventional processes, less weight and has an increased resistance to corrosion.

The primary long and short term advantages of high strength concrete are, low creep and shrinkage, higher stiffness, higher elastic modulus, higher tensile strength, higher durability (resistance to chemical attacks) and higher shear resistance. In addition, high strength concrete reduces the size of the member, which in turn reduces the form size, concrete volume, construction time, labour costs and dead load. Reducing the dead load reduces the number and size of the beams, columns and foundations (lightweight structure). Thus there is a positive impact on reduction of maintenance and repair costs and an increase in rentable space. Other, yet to be discovered, advantages may also exist. High strength concrete has definite advantages over normal strength concrete.

It is generally accepted that helical confinement increases the strength and ductility of confined concrete better than rectangular ties. Helical reinforcement increases the ductility and compressive strength of concrete under compression by resisting lateral expansion due to Poisson's effect. In this study helical reinforcement is used in the compression zone of over-reinforced high strength concrete beams. The effectiveness of helical confinement depends on variables such as helical pitch and diameter.

\section{High strength concrete and steel}

The construction industry's desire for Lightweight structure is driving manufacturers to develop better and stronger materials to facilitate more efficient designs. In recent years, a significant improvement in the properties of reinforcing bars has been achieved and advances in Australian technology have made the use of $500 \mathrm{~N}$ grades common. High strength $500 \mathrm{~N}$ steel contains a 
high percentage of carbon and has a yield strength greater than $500 \mathrm{MPa}$. High strength steel reduces the main reinforcement ratio required for designing reinforced concrete and also reduces steel congestion in beams, columns, slabs, and beam to column connections. As a result, the volume of steel is reduced compared to normal strength steel which is a significant cost saving.

High strength steel has a number of advantages, including strength, reliability, ductility, bending strength, durability, economy, lighter in weight, corrosion resistant, and radiation free [2]. The strength of material and its ductility are often inversely related, that is, by increasing strength, ductility is reduced. However, new advances in material science could produce reinforcing bars that have higher strength and higher ductility. It will be great innovation if material science can produce high strength steel without compromising ductility.

High strength concrete has characteristics that cannot be found in normal concrete. A huge volume of concrete is produced in the world every year to construct bridges, high rise structures, and waste water treatment plants. However, the costs of rehabilitation and replacing are very high, for example in the United States about $\$ 500$ billion is needed just to replace existing bridges and highways [3]. There is a need to reduce construction or rehabilitation costs through utilising the new technology of high strength concrete.

There is a belief that taking the strength as an indicator of high strength concrete is more reliable than its performance (high performance concrete) because measuring performance is very difficult compared to measuring strength. However, the title "high strength concrete" is not an indicator of its strength only but also of its high quality and durability. Therefore, this research paper uses the term "high strength" rather than "high performance" concrete.

\section{Ductility}

There are a few ways of improving the ductility of concrete in compression, providing longitudinal compression reinforcement, using randomly oriented steel fibre, or installing a helical or tie confinement in the compression zone. A comparison between them to find the most effective way is presented below.

Helical reinforcement can be used to achieve the required ductility. It is generally accepted that helical confinement is more effective than rectangular ties in increasing the strength and ductility of confined concrete. Hatanaka and Tanigawa [4] stated that the lateral pressure produced by a rectangular tie is about 30 to 50 percent of the pressure introduced by a helix. This is in agreement with the experimental research conducted by Chan [5], who showed that the efficiency of tie confinement is $50 \%$ of the helical confinement for the same lateral reinforcement ratio. The effectiveness of helix applies to concrete in compression for both beams and columns. The reason why helix is more effective than tie is because it applies a uniform radial stress along the concrete member, whereas a rectangle tends to confine the concrete, mainly at the corners. Thus, the effective area of concrete at the cross section is reduced because the pressure will tend to bend the sides of the tie outwards due to their low stiffness compared with the four corners, as shown in Figure 1. As a result, a significant 
portion of concrete in the cross section will be effectively unconfined. On the other hand the arching of concrete between the ties reduces the effective confined concrete at the level of the concrete member length. Thus using helical confinement in the compression zone of rectangular beams is more effective than rectangular and square ties even though there is a very small portion of unconfined concrete in compression.

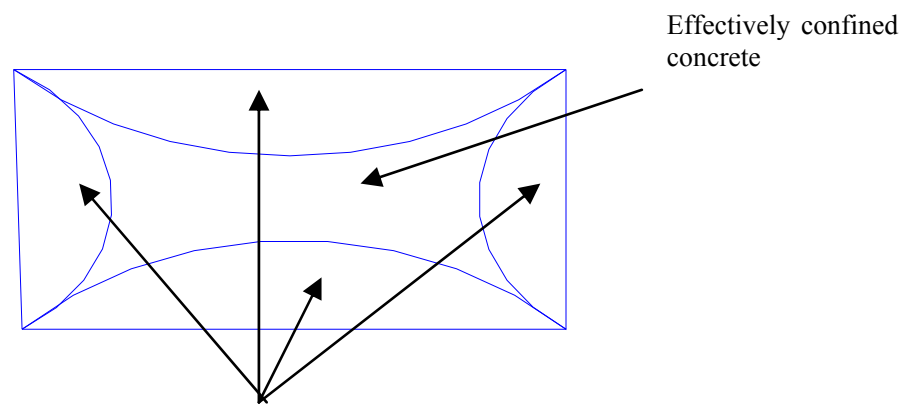

Unconfined concrete at the rectangular tie confinement

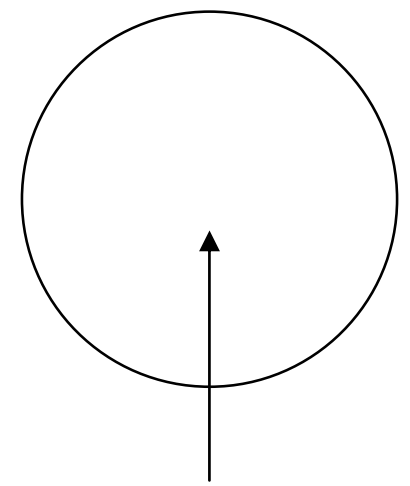

Effectively confined concrete for helix confinement

Figure 1: Effectively confined concrete for helix and rectangular tie.

Shah and Rangan [6] tested 24 groups of beams to compare their ductility. The tests were designed to be under four point loading to ensure failure in the central zone of constant moment. This zone contained various volumes of closed stirrups, different amounts of steel fibres or different volumes of compression longitudinal reinforcement. The test results showed that the ductility of a beam confined with stirrups has 10 times the ductility of the control beams (without any ductility reinforcement), while the fibres increased the ductility 4.5 times and the compression longitudinal reinforcement increased the ductility by twice 
that of the control beam. These results show that confinement with stirrups enhances ductility more than both the compression longitudinal reinforcement and the steel fibres. Also the beams, which had longitudinal compression reinforcement failed earlier because this type of reinforcing tends to buckle prematurely. Based on the experimental programme conducted by Shah and Rangan [6], confinement in the compression zone of a beam is more efficient than steel fibres or longitudinal compression reinforcement. Design standards such as ACI 318R-02 [7] encourage the use of the helix confinement rather than tie.

\section{Experimental program}

Extensive investigation was carried out on full scale beams to study how different variables affected the behaviour of over-reinforced HSC helically confined beams. In this research paper, three beams, $4000 \mathrm{~mm}$ long by $200 \mathrm{~mm}$ wide by $300 \mathrm{~mm}$ deep, with $3600 \mathrm{~mm}$ clear span were subjected to four point loading, with an emphasis placed on midspan deflection. Table 1 shows longitudinal reinforcement details of tested beams and table 2 shows reinforcement ratio details. A helix confinement was installed at the compression zone, where the outside diameter of confined core was kept consistent at $160 \mathrm{~mm}$ for all beams. Figure 2 shows fixing the helical

Table 1: $\quad$ Reinforcement ratio details of tested beam.

\begin{tabular}{|l|l|l|l|}
\hline Specimen & $\begin{array}{l}\text { Tensile } \\
\text { reinforcement }\end{array}$ & $\begin{array}{l}\text { Cross-section area } \\
\text { of reinforcement } \\
\text { steel, } \mathrm{A}_{\mathrm{s}},(\mathrm{mm})\end{array}$ & $\begin{array}{l}\text { Yield strength, } \\
\mathrm{f}_{\mathrm{y}}(\mathrm{MPa})\end{array}$ \\
\hline Beam 1 & 4N32 & 3217 & 500 \\
\hline Beam 2 & 4N32 & 3217 & 500 \\
\hline Beam 3 & 4N32 & 3217 & 500 \\
\hline
\end{tabular}

Table 2: Helical details of the tested beam.

\begin{tabular}{|l|l|l|l|l|}
\hline Specimen & $\begin{array}{l}\text { Effective depth, } \\
\mathrm{d}(\mathrm{mm})\end{array}$ & $\begin{array}{l}\text { Actual } \\
\text { reinforcement } \\
\text { ratio, } \rho\end{array}$ & $\rho_{\max } *$ & $\rho / \rho_{\max } *$ \\
\hline Beam 1 & 235 & 0.068 & 0.046 & 1.47 \\
\hline Beam 2 & 235 & 0.068 & 0.046 & 1.47 \\
\hline Beam 3 & 235 & 0.068 & 0.046 & 1.47 \\
\hline
\end{tabular}

${ }^{*} \rho_{\max }=$ Maximum allowable tensile reinforcement as defined by AS 3600 . 
reinforcement. The concrete cover was kept consistent at $20 \mathrm{~mm}$ for all beams. The aim of the experimental program in this study is to investigate the behaviour of over-reinforced HSC helically confined beams and determine the effect of helix confinement and its pitch on strength and ductility. In the test program reported herein, a total of three beams were cast using different pitches, namely 25,50 and $75 \mathrm{~mm}$. Table 3 shows helical details of the tested beams. All three beams had the same dimensions. Each beam was reinforced with 4N32 bars (32 mm deformed bars of $500 \mathrm{MPa}$ tensile strength and of normal ductility).

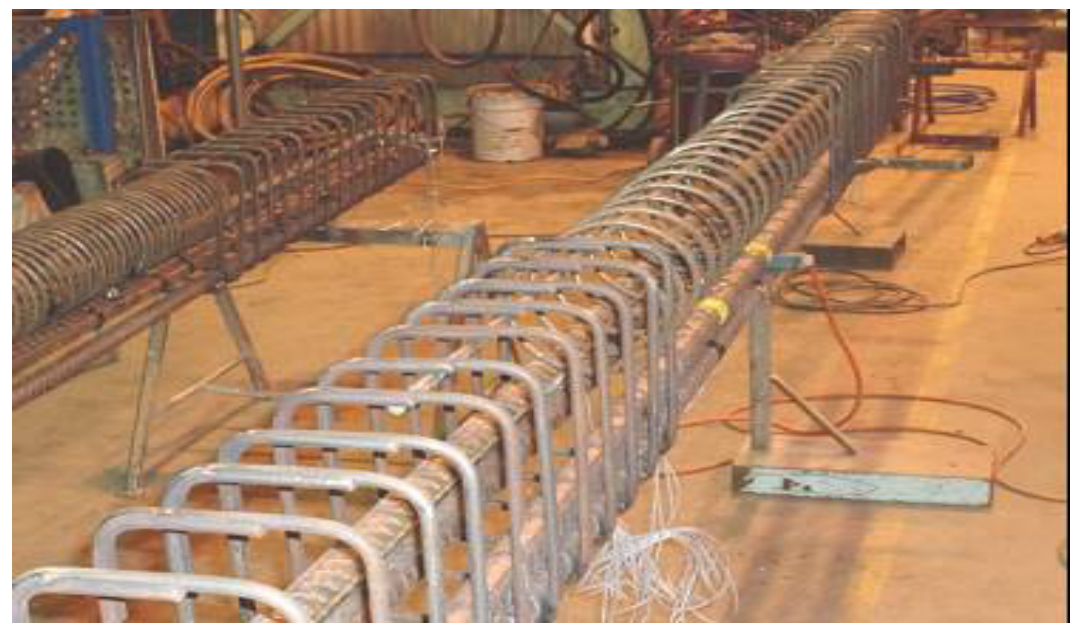

Figure 2: Fixing the helical reinforcement.

Table 3: Helical details of the tested beam.

\begin{tabular}{|l|l|l|l|l|}
\hline Specimen & $\begin{array}{l}\text { Helical yield } \\
\text { strength, } \\
\mathrm{MPa}\end{array}$ & $\begin{array}{l}\text { Helical } \\
\text { diameter, } \mathrm{mm}\end{array}$ & $\begin{array}{l}\text { Helical } \\
\text { pitch, } \\
\mathrm{mm}\end{array}$ & $\begin{array}{l}\text { Helical } \\
\text { reinforce- } \\
\text { ment ratio }\end{array}$ \\
\hline Beam 1 & 310 & 12 & 25 & 0.120 \\
\hline Beam 2 & 310 & 12 & 50 & 0.060 \\
\hline Beam 3 & 310 & 12 & 75 & 0.040 \\
\hline
\end{tabular}

Stirrups of plain $10 \mathrm{~mm}$ diameter (250 MPa tensile strength) were provided at either third end of the beams at a spacing of $80 \mathrm{~mm}$. Two $10 \mathrm{~mm}$ bars were installed at the top of the beams at either third in order to keep the ties in-place. For the three beams the helix was made of $12 \mathrm{~mm}$ deformed bars. The concrete used in this experimental program was supplied as ready mix by a local supplier and was specified to gain $100 \mathrm{MPa}$. The concrete compressive strength of the three beams was $105 \mathrm{MPa}$. Figure 3 shows the Beam loading. The mid span deflection of the beam was measured using linear variable differential transformers (LVDTs). 


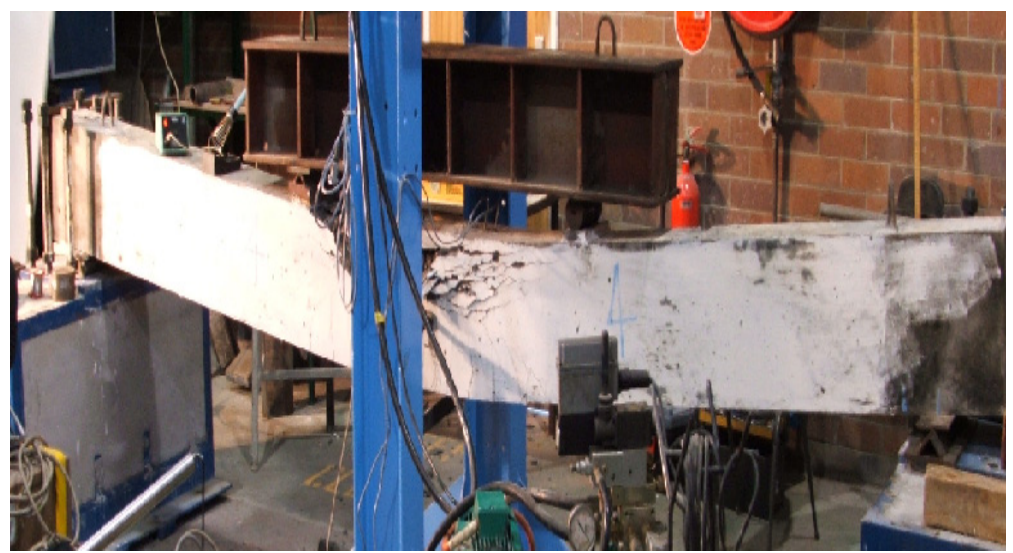

Figure 3: $\quad$ Beam loading.

\section{Analysis and discussion}

The behaviour of the helically confined beams is different from unconfined beams because of the spalling off phenomenon. It is to be noted that the load increases as the deflection increase until the concrete cover spalls off, and then the load drops while the midspan deflection increase because of the helical confinement effect. However, the load increased again as the deflection increased until the point where the load decreases gradually as the deflection increases. It is to be noted that the maximum load recorded for beam 1 is greater than the concrete cover spalling off load but for the other beams the maximum load recorded was the load at concrete cover spalling off. Figures 4, 5 and 6 show the complete recorded data of the mid-span deflection load for the three tested beams. These Figures illustrate the load mid-span deflection for Beams 1, 2, 3, remarkable effect that helical pitch has on displacement ductility could be noted. Beams, which have helical pitches of 25,50 and $75 \mathrm{~mm}$ failed in a ductile manner. The level of ductility depends on helical pitch. It has been observed that helical pitch is an important parameter in enhancing the strength and ductility of beams. This observation is based on the results of an extensive experimental programme.

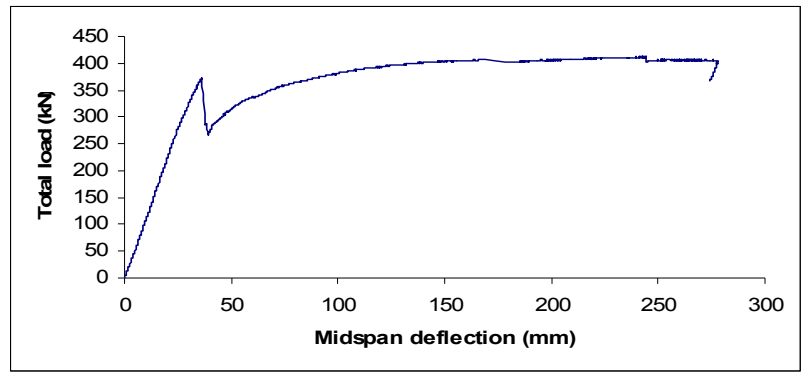

Figure 4: $\quad$ Load midspan deflection curve for beam 1. 


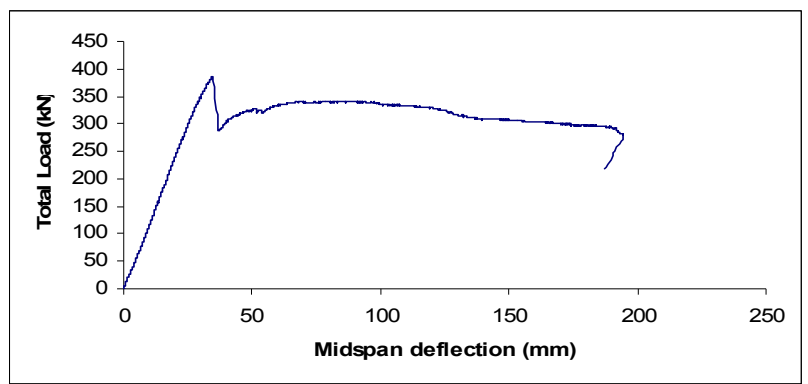

Figure 5: $\quad$ Load midspan deflection curve for beam 2.

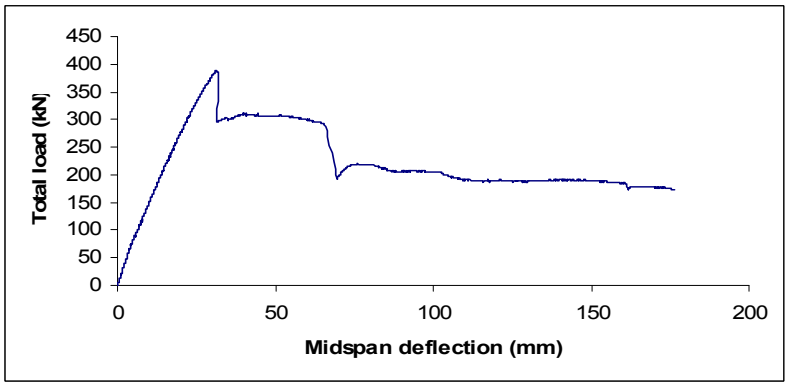

Figure 6: $\quad$ Load midspan deflection curve for beam 3.

Table 4 displays the comparison between the calculated bending moment according to the AS 3600 [1] recommendation, and the experimental moment for confined beams. It has to be noted that the experimental moment is significantly higher than the calculated moment capacity by $30 \%$ to $40 \%$. However, the ductility of these beams was significantly enhanced because of the helical confinement installed in the compression zone with an effective pitch at the mid span of the beam. It has to be noted that using the AS 3600 [1] recommendation for predicting the flexure strength capacity of over reinforced helically confined HSC beams is safe but not economic because the AS 3600 [1] recommendation is based on the behaviour of over-reinforced beams without helical confinement, where there is lack of ductility. It is uneconomical to predict the flexure strength capacity of over-reinforced helically confined HSC beams using the AS 3600 [1] recommendation unmodified because over-reinforced beams behave differently than over-reinforced helically confined HSC beams. Once the ductility of an over-reinforced beam is improved by installing helical confinement in the compression zone then there is a need to improve the predictive method to minimise the differences between the experimental and predicted results. The test results of this study proved that the ductility of over-reinforced helically confined HSC beams was significantly enhanced. As the behaviour of an overreinforced beam differs from an over-reinforced helically confined HSC beams, so their design processes are also different. Thus there is a need to develop a 
simple method with an appropriate assumption for predicting the flexural strength capacity of over-reinforced helically confined HSC beams.

Table 4: $\quad$ Comparison between calculated and experimental moment.

\begin{tabular}{|l|r|r|r|r|}
\hline Specimen & $\begin{array}{l}\text { Ku } \\
\text { neutral axis } \\
\text { parameter }\end{array}$ & $\begin{array}{l}\text { Mcal (kN.m) } \\
\text { calculated } \\
\text { moment }\end{array}$ & $\begin{array}{l}\text { Mexp (kN.m) } \\
\text { experimental } \\
\text { moment }\end{array}$ & $\begin{array}{l}\text { Mexp/ } \\
\text { Mcal }\end{array}$ \\
\hline Beam 1 & 0.562 & 176.6 & 246.6 & 1.40 \\
\hline Beam2 & 0.562 & 176.6 & 229.8 & 1.30 \\
\hline Beam3 & 0.562 & 176.6 & 231.6 & 1.31 \\
\hline
\end{tabular}

\section{Conclusion}

The experimental component of this study involved three full size overreinforced helically confined HSC beams. Their cross section was $200 \times 300 \mathrm{~mm}$, the length was $4 \mathrm{~m}$ and the clear span was 3.6 metres. They were subjected to four point loading with an emphasis on midspan deflection. The following conclusions are drawn from this study:

The test results proved that the behaviour of an over-reinforced helically confined HSC beam is dissimilar to over-reinforced concrete beams. The overreinforced helically confined HSC beams fail in a ductile mode. The significant improvements to ductility by helical confinement in the compression zone and the predictive process encourage taking new and different method for predicting the moment capacity and designing over-reinforced helically confined HSC beams.

The beams with helical pitch of 25, 50 and $75 \mathrm{~mm}$ have shown to be ductile and the level of ductility is based on the helical pitch. The helixes effectively confined the compressive region when the helical pitch was reduced. It is interesting to note that the displacement ductility increases as the helical pitch decreases. In other words, displacement ductility index is inversely proportional with the helical pitch. However the significant effect of the helix diameter on the displacement ductility is only when the helix pitch is between $25 \mathrm{~mm}$ and $50 \mathrm{~mm}$.

High strength concrete and high strength steel have benefits for different structures such as high rise structures and larger span girders but these materials lack ductility. This study has shown that helical confinement in the compression zone of beams enhances the strength and the ductility of over-reinforced HSC beams. However, as development in material science and computational technology is somewhat unimaginable, it is believed that over-reinforced helically confined HSC beams will become a very important design concept for safeguarding structures. The experimental testing conducted in this research proved that using helices to enhance the characteristics of high strength concrete beams is an effective technique. 


\section{References}

[1] AS3600. Australian Standard for Concrete Structures. Standards Association of Australia. North Sydney, 2001.

[2] AS/NZS 4671. Australian Standards for Steel Reinforcing Materials. Standards Association of Australia, North Sydney, 2001.

[3] Nawy, E. G. (2001). "Fundamentals of High-Performance Concrete." Second edition. John Wiley \& Sons, Canada.

[4] Hatanaka, S. and Tanigawa, Y. (1992). "lateral pressure requirements for compressive concrete." Proceedings of $10^{\text {th }}$ World Conference on Earthquake Engineering, Madrid, 2603-2608.

[5] Chan, W. W. L. (1955). "High-Strength Concrete: The Hong Kong Experience." Magazine of Concrete Research, 7(21), 121-132.

[6] Shah, S. P. and Rangan, B. V. (1970). "Effects of Reinforcements on Ductility of Concrete." Journal of The Structural Division, 96(6), 11671184.

[7] ACI 318-02. Building Code Requirements for Structural Concrete. American Concrete Institute, Michigan, 2002. 